Article

\title{
Estimation of Fatigue Crack Growth Rate for 7\% Nickel Steel under Room and Cryogenic Temperatures Using Damage-Coupled Finite Element Analysis
}

Seul-Kee Kim ${ }^{1}$, Chi-Seung Lee ${ }^{1}$, Jeong-Hyeon Kim ${ }^{1}$, Myung-Hyun Kim ${ }^{1}$, Byeong-Jae Noh ${ }^{2}$, Toshyuki Matsumoto $^{3}$ and Jae-Myung Lee ${ }^{1, *}$

1 Department of Naval Architecture and Ocean Engineering, Pusan National University, Busan 609-735, Korea; E-Mails: kfreek@pusan.ac.kr (S.-K.K.); victorich@pusan.ac.kr (C.-S.L.); honeybee@pusan.ac.kr (J.-H.K.); kimm@pusan.ac.kr (M.-H.K.)

2 Hyundai Heavy Industries, Ulsan 682-792, Korea; E-Mail: bjnoh@hhi.co.kr

3 Research Institute of ClassNK, Tokyo 102-8567, Japan; E-Mail: rx-sec@classnk.or.jp

* Author to whom correspondence should be addressed; E-Mail: jaemlee@pusan.ac.kr; Tel.: +82-51-510-2342; Fax: +82-51-512-8836.

Academic Editor: Hugo F. Lopez

Received: 10 February 2015 / Accepted: 10 April 2015 / Published: 20 April 2015

\begin{abstract}
In this study, fatigue crack growth rates (FCGR) of 7\% nickel steel at room and cryogenic temperatures were evaluated using damage-coupled finite element analysis (FEA). In order to perform the computational fatigue analysis effectively, methods for coupling damage to FEA are introduced and adopted. A hybrid method including the damage-coupled constitutive model and jump-in-cycles procedure was implemented into the ABAQUS user-defined material subroutine. Finally, the represented method was validated by comparing its results with the FCGR test results for 7\% nickel steel under room and cryogenic temperatures. In particular, $\mathrm{d} a / \mathrm{d} N$ versus $\Delta K$ and the crack length versus the number of cycles were compared.
\end{abstract}

Keywords: fatigue crack growth rate; damage mechanics; 7\% nickel steel; cryogenic temperature; ABAQUS user-defined material subroutine (UMAT) 


\section{Introduction}

Industrial structures, including ships and offshore structures, are subject to periodic and arbitrary loadings. These phenomena lead to crack propagation and fracture of the structures. In order to prevent such catastrophic disaster, fatigue analysis and fatigue life assessment should be carried out prior to the design steps.

Miner's accumulative damage calculation and Goodman fatigue calculation are the representative fatigue life evaluation methods under regular and irregular cyclic loading. If there is an initial crack included in the material or structural member, the fatigue life and fatigue crack growth rate can change under the operating environments of the structure. For this reason, the fatigue crack growth rate (FCGR) test is commonly adopted to investigate the crack growth characteristics of materials [1].

The estimation of FCGR characteristics has mainly been performed by an experimental approach. Through the test, the correlation between the crack growth rate $\mathrm{d} a / \mathrm{d} N$ and the applied stress intensity factor range $\Delta K$ can be estimated [2].

However, it requires enormous time and cost to establish the required experimental facilities and conditions. In addition, it is extremely difficult to reproduce harsh environments such as cryogenic and high temperatures. For this reason, there are many limitations to carrying out the FCGR test effectively. As a result, computational simulation has been considered as an alternative method to solve these problems.

In computational simulation, two kinds of approaches have been principally adopted, namely, a cohesive zone model (CZM) and an extended finite element method (XFEM).

In the CZM theory, a crack is propagated through the separation surface (or cohesive zone) when the cohesive separation force is greater than the cohesive traction force. The crack propagation problems of brittle/cementitious materials, in which a nonlinear zone ahead of the crack tip is generated because of plasticity and microcracking near the cracked region, can be analyzed using the CZM [3]. There are many researchers who solve the fatigue crack growth problem using the CZM. For example, de-Andres et al. have solved a three-dimensional fatigue crack phenomenon and estimated the fatigue life of an aluminum shaft under axial loading using a three-dimensional cohesive element and an irreversible cohesive law [4]. Yang et al. have proposed a simulation method for fatigue crack initiation and propagation in quasi-brittle materials using the CZM [5], and Roe and Siegmund have studied fatigue crack growth along an interface using the actual process of material separation, and not by using Paris' law [6]. In their research, it was found that the traction-separation behavior does not follow a predefined traction-separation path as posited by the classical CZM. Hence, an improved CZM has been proposed on the basis of three types of viewpoints, namely, (i) the consideration and application of a traction-separation law considering unloading in both normal and shear separation in the cohesive zone; (ii) the development of an evolutionary damage law in order to analyze failure under subcritical loading in dependence of the accumulated separation and the current resultant traction in the cohesive zone; and (iii) the establishment of a contact model. In addition, Bouvard et al. have carried out a numerical analysis of the fatigue and creep-fatigue crack growth of single crystal superalloys using an irreversible CZM [7]. In order to calculate the fatigue damage accumulation under cyclic loads, a damage-coupled CZM has been proposed, and damage accumulation and stagnation phenomena under loading and unloading conditions have been quantitatively predicted. Ural et al. have developed a damage-based 
cohesive model in which the coupled model is fabricated by the combination of the linear damage-dependent traction-separation relation and the damage evolution equation [8].

On the other hand, the handicaps of the classical finite element method (FEM) for crack propagation simulation, such as an impractical crack growth shape and node singularity, have been improved by the XFEM. For using XFEM, a standard displacement-based approximation has been enriched near a crack by incorporating both the discontinuous fields and the near-tip asymptotic fields through a partition of unity method. On the basis of this technique, the entire crack is represented independently of the mesh; hence, a remeshing technique is not necessary to describe the crack growth [9]. The XFEM is most recent proposed method, and outstanding studies have been carried out since 1999. Stolarska et al. have developed a level set method (LSM)-coupled XFEM algorithm [10]. The LSM and XFEM were adopted to represent the crack tip location prior to the crack growth and the rate of crack growth, respectively. In addition, Sukumar et al. have proposed a fast marching method (FMM)-coupled XFEM technique [11]. In order to describe the crack front in an FE model, the FMM was combined with Paris' law. Moreover, the stress intensity factor for planar three-dimensional cracks was calculated, and the fatigue crack growth was simulated using the XFEM. Shi et al. have programmed an ABAQUS user-defined material subroutine (UMAT) and element subroutine (UEL) for the practical simulation of fatigue crack growth of a compact tension specimen using the FMM-XFEM technique [12].

The aforementioned studies using both types of methods show good agreement with the fatigue crack growth experiments using a compact tension specimen, a notched plate, etc. In other words, the correlation between $\mathrm{d} a / \mathrm{d} N$ and $\Delta K$ in the stable crack growth region, i.e., region II, has been well predicted. However, these methods require experiments prior to simulation to identify the material parameters of the governing equation, which is a function of the critical stress intensity factor, the cohesive fracture energy variable, and the critical crack opening value. Although these numerical methods have been verified sufficiently for simulating fatigue crack growth, a large number of experiments are required to determine the moment and realm of crack occurrence while considering information about the initial crack such as shape and position.

In contrast with these techniques, damage mechanics has been introduced as a new method for expressing the fatigue crack growth phenomena. Damage mechanics is based on thermodynamic micromechanical approaches, and has provided governing equations that can be incorporated into the material constitutive equation to express the material degradation that causes crack initiation and propagation [13-17].

One of the distinctive factors of damaged materials under arbitrary loads is material degradation due to void and slip. In particular, the elastic stiffness variable/matrix is degraded because of these micro-defects. There is an inverse relationship between elastic stiffness and material defects. In the case of the damage mechanism, degradation of elastic stiffness and void/slip growth can be represented by an effective elastic stiffness model and a damage evolution model, respectively. On the basis of the correlation between these two models, the material/structural degradation under various loads, such as fatigue, creep, brittle, and ductile failures, can be evaluated and predicted quantitatively [18-20]. Furthermore, in order to analyze the damage/failure behavior of materials precisely, it is crucial to select a suitable damage evolution model from among the possible choices.

There are a few damage evolution models that describe the various types of material failures, such as elastic-plastic ductile damage [19,21-23], fatigue damage [24-27], creep and creep-fatigue 
damage [28-30], and elastic-brittle damage [31-34]. In the case of low-cycle fatigue, some research has been performed. Hamon et al. proposed a damage model for fatigue crack propagation. The model is based on two damage mechanisms that consider static and cyclic damage on fatigue crack propagation. In this study, $\mathrm{d} a / \mathrm{d} N$ and $\Delta K$ curves at different load ratios were obtained numerically (typical results for FCGR tests) and the proposed model showed good agreement with experimental results. However, there are few studies on how to predict fatigue life under high-cycle fatigue for various types of metal and nonmetal materials. Additional mechanisms such as two-scale damage are required to express crack propagation under high-cycle fatigue that occurs in an elastic regime.

Three difficulties must be overcome to computationally assess the fatigue crack grow rate using a finite element analysis (FEA) based on damage mechanics: (i) the selection of an appropriate material constitutive model to express the material's plastic behavior and evolution of the damage; (ii) a method for simulating the crack propagation based on the calculation results using the material constitutive model; and (iii) the time costs for the computation, which can be more difficult in the case of high cycle fatigue problems.

In the authors' previous study, simulations of the crack propagation were performed under monotonic loading conditions at room and cryogenic temperatures and moreover, the fracture capacities of SUS304L were also estimated computationally at both temperatures [35]. A previously proposed method based on a material constitutive model is verified by the comparison of the results, such as the strain energy release rate, $G_{I C}$, failure mode, and force-displacement relationship, from the experimental and computational fracture tests. This computational method could be a solution for first two difficulties mentioned above. The constitutive model used sufficiently expressed the materials' plastic behavior including strong hardening at cryogenic temperatures and the evolution of damage of SUS304L. Crack propagations, including fracture mode, are also simulated based on a calculated damage variable using the element weakening method $[35,36]$. Therefore, in the present study, for the numerical estimation of fatigue fracture, the aforementioned computational method using a material constitutive model including damage evolution model is employed again. In addition, the jump-in-cycles procedure and a numerical approach rearranging critical damage are employed for fatigue damage analysis, in order to reduce the computational times and to consider the fatigue fracture phenomenon differently from ductile fracture under static loading, respectively (these numerical approaches can be solution for the last difficulty as presented before). The aforementioned procedure and numerical approach for fatigue damage analysis are also implemented in ABAQUS UMAT. Finally, in the present study, a computational FCGR tests using the proposed ABAQUS UMAT for 7\% nickel steel are carried out at room and cryogenic temperatures. The obtained numerical results were verified by comparing them with the experimental results.

\section{Experimental FCGR Tests}

Before the numerical evaluation of the fatigue crack growth rate for $7 \%$ nickel steel, experimental tests are performed. The experimental test results are compared with the numerical results in order to validate the computational method proposed in the present study. Compact tension (CT) type specimens for fatigue tests were tested at both the room temperature and the cryogenic temperature $\left(-163{ }^{\circ} \mathrm{C}\right)$. The cryogenic temperature was selected in consideration of the temperature at which liquefied natural gas (LNG) is stored. 
The FCGR test is conducted according to ASTM E647 [37]. The test method involves cyclic loading of notched specimens that have been acceptably precracked by fatigue. The crack size is measured, either visually or by an equivalent method, as a function of the elapsed fatigue cycles, and these data are subjected to numerical analysis to establish the rate of crack growth. Crack growth rates are expressed as a function of the stress-intensity factor range, $\Delta K$, which is calculated from expressions based on linear elastic stress analysis.

\subsection{Test Specimens}

Nickel is recognized to enhance fracture toughness of materials at low temperatures. Therefore, nickel is widely employed as an ingredient in materials for constructing industrial structures, such as LNG carrier storage systems. In particular, 7\% nickel steel has being recently applied in LNG carrier storage systems in order to replace $9 \%$ nickel steel, which requires a considerable amount of expensive welding materials. However, only a few studies have been carried out to assess the fracture capacity of $7 \%$ nickel steel at both the room temperature and the cryogenic temperature.

The chemical composition of $7 \%$ nickel steel, which is selected for the study of the fatigue crack growth rate test, is summarized in Table 1.

Table 1. Chemical composition of 7\% nickel steel (wt. \%).

\begin{tabular}{cccccccc}
\hline Element & $\mathbf{C}$ & $\mathbf{S i}$ & $\mathbf{M n}$ & $\mathbf{P}$ & $\mathbf{S}$ & $\mathbf{C u}$ & $\mathbf{N i}$ \\
\hline weight \% & 0.05 & 0.05 & 0.80 & 0.001 & 0.001 & 0.03 & 7.13 \\
\hline Element & $\mathbf{C r}$ & $\mathbf{M o}$ & $\mathbf{N b}$ & $\mathbf{V}$ & $\mathbf{T i}$ & \multicolumn{2}{c}{ Sol. Al } \\
\hline weight $\%$ & 0.41 & 0.04 & $<0.003$ & $<0.003$ & $<0.003$ & 0.030 \\
\hline
\end{tabular}

The geometry of the standard CT specimen is shown in Figure 1 based on ASTM E647 [37]. Thickness $B$ and width $W$ may be varied independently within the following limits. For CT specimens, it is recommended that the thickness be within the range $\mathrm{W} / 20 \leq B \leq \mathrm{W} / 4$. Specimens having thicknesses up to and including W/2 may also be employed.

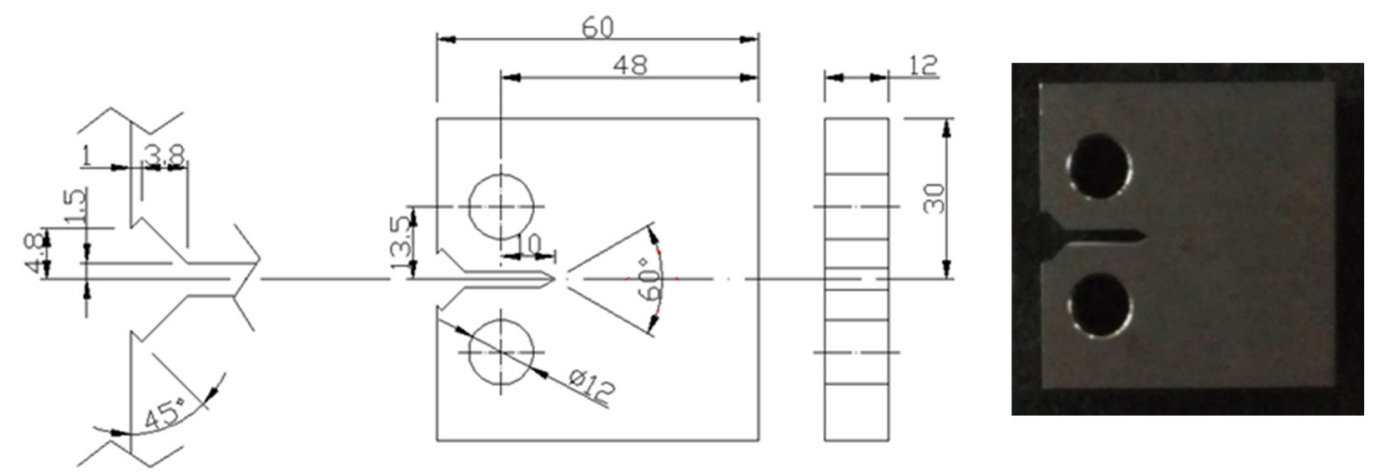

Figure 1. Geometry of the test specimen [37].

The fatigue precrack is made in the specimen using the $K$ (stress intensity factor)-decreasing procedure based on ASTM E647 [37]. $K$-decreasing procedure requires that the final $K_{\max }$ during precracking shall not exceed the initial $K_{\max }$ for which test data are to be obtained. Therefore, forces corresponding to higher $K_{\max }$ values used to initiate cracking at the machined notch and the force range 
shall be stepped-down. Figure 2 shows the actual stepped-down force histories for precracking according to $K$-decreasing procedure. The frequency of fatigue loading is $10 \mathrm{~Hz}$. The initial $K_{\max }$ and final $K_{\max }$ during the $K$-decreasing procedure at both the room temperature and the cryogenic temperature are 34.44 and $31.64 \mathrm{MPa} \sqrt{m}$ and 32.57 and $31.31 \mathrm{MPa} \sqrt{m}$, respectively.
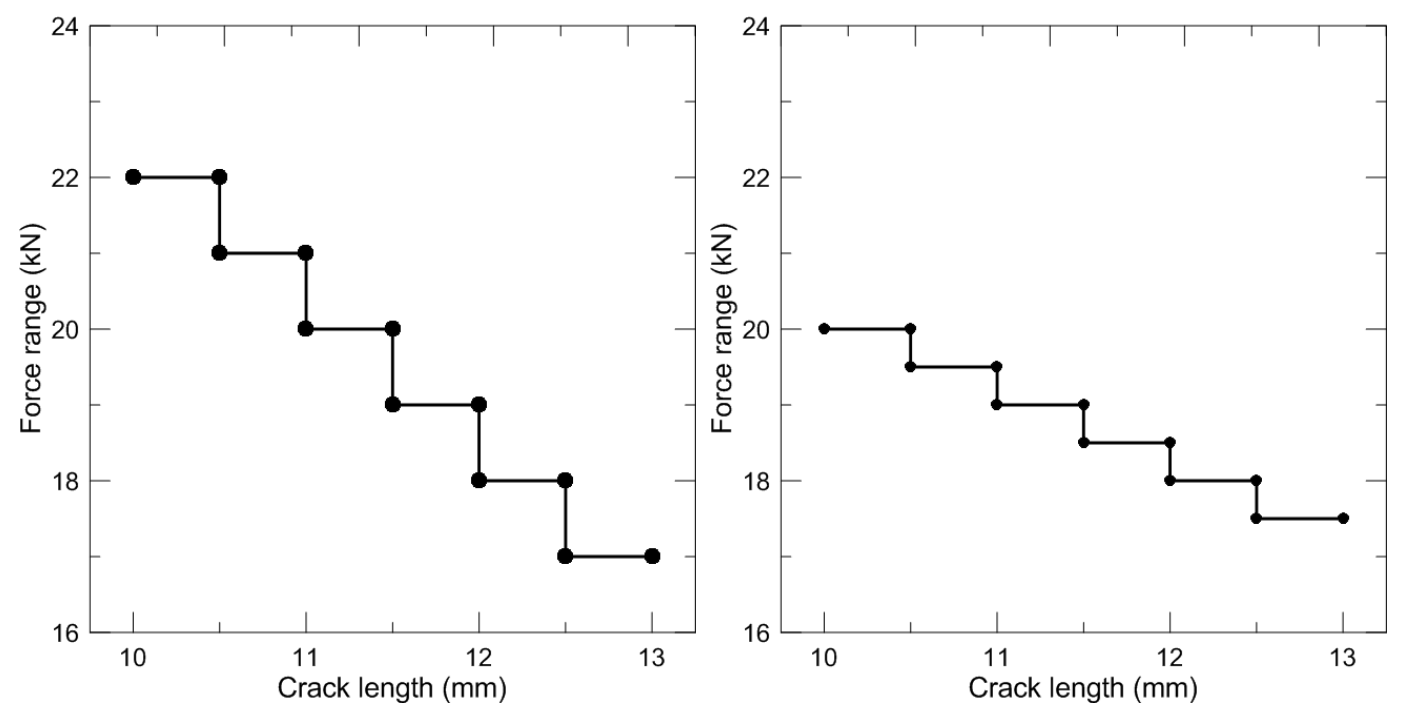

Figure 2. Actual K-decreasing by stepped force shedding at room temperature (left) and cryogenic temperature (right).

\subsection{Test Facilities}

Servo-hydraulic testing machines with a maximum load capacity of \pm 50 tons (IST-8800) were used for the fatigue crack growth rate test of $7 \%$ nickel steel. To maintain the cryogenic temperature, a special-purpose cryogenic chamber was fabricated and installed in the testing machine.

All the tests were terminated at the point where a through-width fracture occurred. A load control mode was used a $10 \mathrm{~Hz}$ as same as precracking procedure. The maximum loads of $18 \mathrm{kN}$ are applied to specimens tested at both the room temperature and the cryogenic temperature. The stress ratios are zero for both tests.

\subsection{Methods for Measurement of Crack Length}

The crack length during the test is measured using a compliance method based on ASTM E647 [37]. The results of the fatigue crack growth tests are used to analyze the relationships between the crack length $(a)$ and the number of cycles $(N)$, as well as between $\mathrm{d} a / \mathrm{d} N$ and the stress intensity factor range $(\Delta K)$. The empirical formulae for calculating the crack length of the compact tension specimen are as follows ASTM E647 [37]:

$$
\begin{gathered}
\alpha=a / W=C_{a}+C_{b} u_{x}+C_{c} u_{x}^{2}+C_{d} u_{x}^{3}+C_{e} u_{x}^{4}+C_{f} u_{x}^{5} \\
u_{x}=\left\{\left[\frac{E v B}{P}\right]^{0.5}+1\right\}^{-1} \text { for } 0.2 \leq a / W \leq 0.975
\end{gathered}
$$


where $a$ is the crack length, $W$ is the width of the specimen, $E$ is the elastic modulus, $v$ is the displacement between the measurement points, $B$ is the specimen thickness, and $P$ is the force. $C_{a} \sim C_{f}$ are the constants determined from the measuring location, as shown in Figure 3 and Table 2.

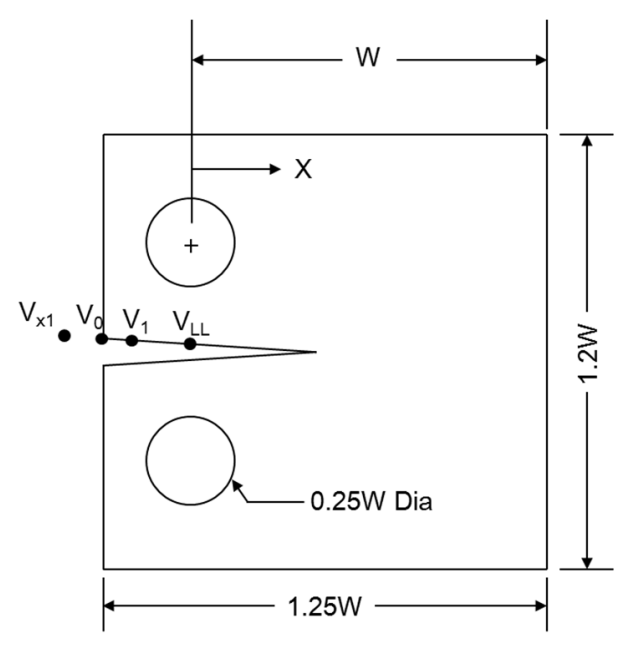

Figure 3. Normalized crack length as a function of plane stress elastic compliance for compact tension specimen ASTM E647 [37].

Table 2. Constants determined from the measuring location for CT specimen ASTM E647 [37].

\begin{tabular}{cccccccc}
\hline Meas. Location & $\boldsymbol{X} / \boldsymbol{W}$ & $\boldsymbol{C}_{\boldsymbol{a}}$ & $\boldsymbol{C}_{\boldsymbol{b}}$ & $\boldsymbol{C}_{\boldsymbol{c}}$ & $\boldsymbol{C}_{\boldsymbol{d}}$ & $\boldsymbol{C}_{\boldsymbol{e}}$ & $\boldsymbol{C}_{\boldsymbol{f}}$ \\
\hline$V_{x l}$ & -0.345 & 1.0012 & -4.9165 & 23.057 & -323.91 & 1798.3 & -3513.2 \\
$V_{0}$ & -0.250 & 1.0010 & -4.6695 & 18.460 & -236.82 & 1214.9 & -2143.6 \\
$V_{1}$ & -0.1576 & 1.0008 & -4.4473 & 15.400 & -180.55 & 870.92 & -1411.3 \\
$V_{L L}$ & 0 & 1.0002 & -4.0632 & 11.242 & -106.04 & 464.33 & -650.68 \\
\hline
\end{tabular}

Another typical result of the fatigue crack growth rate test is the relationship between $\mathrm{d} a / \mathrm{d} N$ and the stress intensity factor range. The linear region of this relationship in the log-log scale can be expressed using the empirical formula known as Paris' law [2]:

$$
\frac{\mathrm{d} a}{\mathrm{~d} N}=C \Delta K^{m}
$$

where $C$ and $m$ are the material parameters determined by the experimental fatigue crack growth test.

The stress intensity factor range $(\Delta K)$ in the plane stress condition can be expressed as follows ASTM E647 [37]:

$$
\Delta K=\frac{\Delta P}{B \sqrt{W}} \frac{(2+\alpha)}{(1-\alpha)^{1.5}}\left(0.886+4.64 \alpha-13.32 \alpha^{2}+14.72 \alpha^{3}-5.6 \alpha^{4}\right)
$$

where $\Delta P$ is the force range, which is the algebraic difference between the maximum and the minimum forces in a cycle. 


\subsection{Test Results and Discussion}

The results of the experimental fatigue crack growth rate tests are shown in Figures 4 and 5. The test results at both temperatures are presented together. Figure 4 shows the relationship between the number of cycles and the crack length. As shown in the figure, 7\% nickel steel exhibits enhanced fracture resistance under fatigue loading at cryogenic temperature.

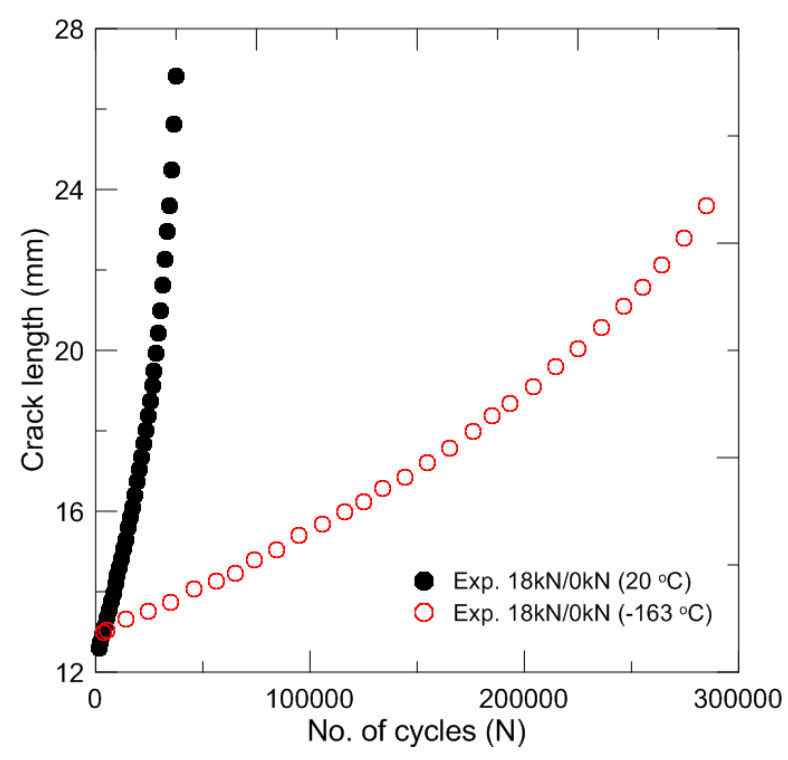

Figure 4. Relationship between the crack length and the number of cycles at the room and cryogenic temperatures.

Figure 5 shows a log-log plot of the relationship between $\mathrm{d} a / \mathrm{d} N$ and $\Delta K$. The material parameters in terms of Paris' law, $C$ and $m$, are determined from this result. The experimental fatigue crack growth rate test results, including the material parameters $C$ and $m$, are summarized in Table 3 .

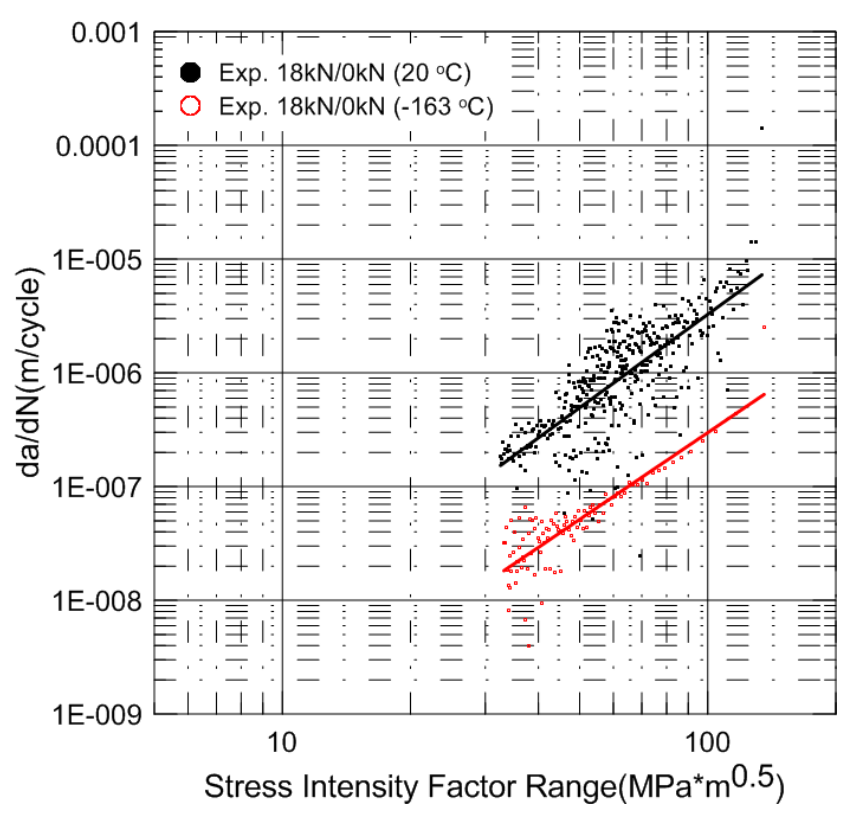

Figure 5. Relationship between $\mathrm{d} a / \mathrm{d} N$ and $\Delta K$ at room and cryogenic temperatures. 
Table 3. Summary of experimental fatigue crack growth rate test results.

\begin{tabular}{ccccccc}
\hline Material & Temperature & Max. Load (kN) & Min. Load $(\mathbf{k N})$ & Cycle $\left(\boldsymbol{N}_{\boldsymbol{f}}\right)$ & $\boldsymbol{C}$ & $\boldsymbol{m}$ \\
\hline \multirow{2}{*}{$7 \% \mathrm{Ni}$} & $\mathrm{RT}$ & 18 & 0 & 40,019 & $2.17 \times 10^{-11}$ & 2.57 \\
\cline { 2 - 7 } & $\mathrm{CT}\left(-163^{\circ} \mathrm{C}\right)$ & 18 & 0 & 349,541 & $21.61 \times 10^{-12}$ & 2.71 \\
\hline
\end{tabular}

In the present study, $\mathrm{d} a / \mathrm{d} N$ and $\Delta K$ curves are obtained from two neighboring points of experimental results as follows:

$$
\begin{gathered}
\mathrm{d} a / \mathrm{d} N=\left(a_{n+1}-a_{n}\right) /\left(N_{n+1}-N_{n}\right) \\
\Delta K=\left(K_{n+1}-K_{n}\right)
\end{gathered}
$$

In Figure 5, scatters are presented around a line representing Paris' Law. The large scatter is explained by Figure 6. Here, assuming that the two neighboring points shown in the green-outlined section in the left frame have almost the same crack length (i.e., $\Delta K$, a function of $\Delta P$ and the crack length, is almost the same) at different numbers of cycles, the related point in the graph of $\mathrm{d} a / \mathrm{d} N$ with respect to $\Delta K$ is located in the green-outlined section in the right frame. As in the previous case, if the two neighboring points have different crack lengths at almost the same number of cycles, scatters appear in Figure 6 (blue-outlined section). The fatigue crack is not propagated at every cycle during the experiments. Therefore, some scatters in Figure 5 are negligible in view of the total fatigue-crack propagation during the FCGR tests, and the relationship between the crack length and number of cycles represented in Figure 4 is not affected by the scatters in Figure 5.

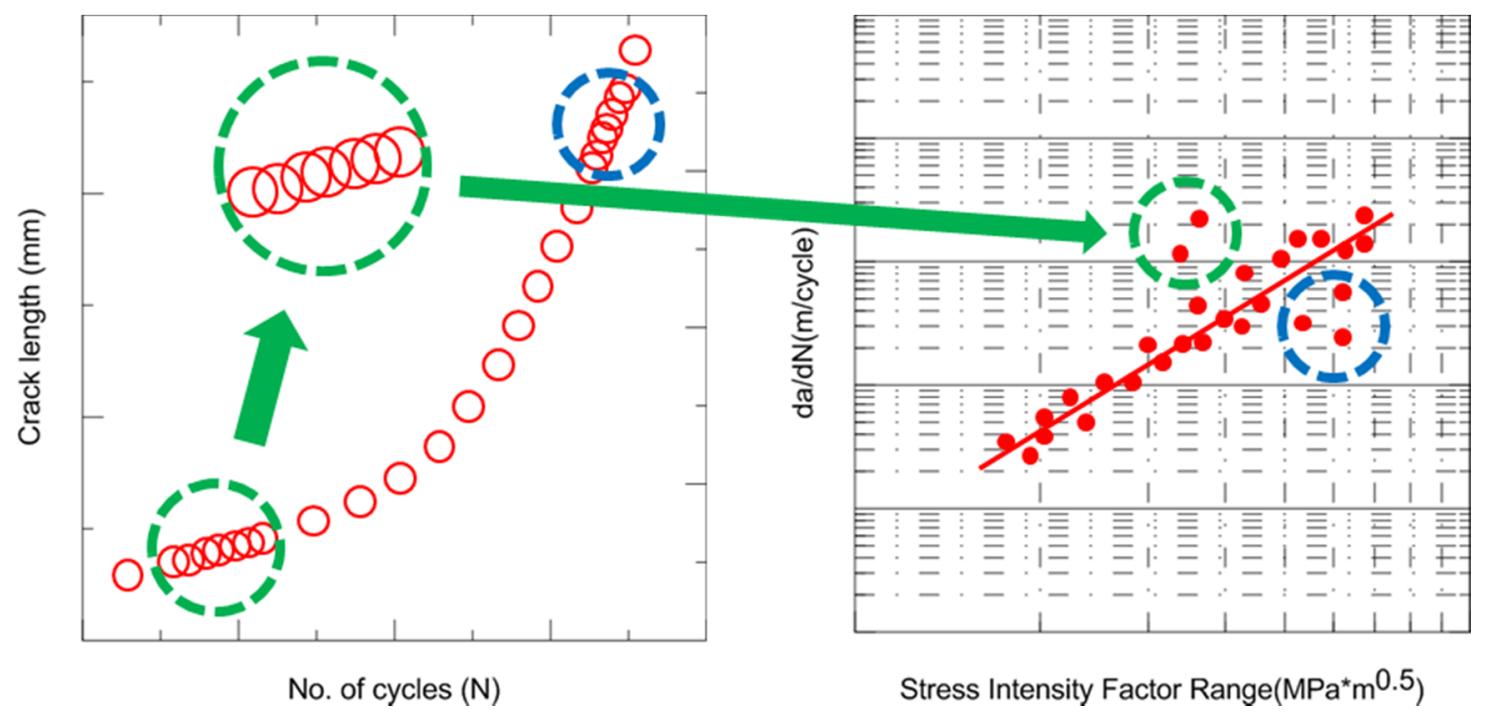

Figure 6. Schematics of scatters induced on $\mathrm{d} a / \mathrm{d} N-\Delta K$ curve.

As shown in the test results, the fracture resistances of $7 \%$ nickel steel under fatigue loading are considerably different between room temperature and cryogenic temperature (see Figure 4). Retained austenite is known to improve the toughness and strength of steels such as nickel-alloyed steels including austenitic stainless steels [35,36,38]. The nickel decreases the temperature of the martensite transformation and thermally stabilizes the austenite. Retained austenite enhances the fracture toughness by strain-induced martensite transformation within the temperature range of room temperature to $70 \mathrm{~K}$. Increasing the content of retained austenite strengthens the effect of the strain-induced martensite transformation and 
thereby elevates the fracture toughness. Notably, these results indicate that both the composition and microstructure can influence low-temperature strengthening mechanisms [39,40]. These phenomena reveal the importance of understanding material nonlinearities, such as temperature dependency, which result in an increased fracture-resistance capacity.

The details of the fatigue crack growth test render it difficult to perform at a low temperature. The reasons for this include the special equipment required, the special care necessary for data acquisition, the cost, and the time needed. However, prior to the industrial utilization of a new type of material, the evaluation of the fracture resistance capacity under fatigue loading is essential for safe design. Therefore, a low-cost, efficient test method is required, particularly for low-temperature conditions.

\section{Coupling Damage Analysis for Computational FCGR Tests}

In the present study, a method for computationally estimating the fatigue crack growth rate was proposed based on a structural damage analysis using FEA. Generally, it is known that there are two types of representative approaches for applying damage variables in conjunction with internal state variables such as the stress and strain to predict the failure of a structure: fully coupled and uncoupled approaches [36].

In an uncoupled approach, the failure prediction of a structure is carried out using a threshold value for the damage, and the damage variable is calculated using a damage evolution equation, with the stress fields obtained from a structural analysis. Although an uncoupled approach is relatively comfortable and can save calculation time, this approach cannot ensure precise results because there is no coupling between the strain and damage field during the structural analysis [17,41,42].

In a fully coupled approach, the damage variable is calculated using a damage evolution equation during a structural analysis, and the stress, strain, and damage fields are mutually affected. Therefore, the full coupling process produces more accurate results, but it requires a relatively large amount of time for the calculation, which is conducted throughout the entire FEA process $[17,41,42]$.

The proposed computational method for estimating the fatigue crack growth rate (FCGR) was carried out by adopting both approaches in computational FCGR tests. A fully coupled analysis was primarily performed during the computational tests, and the damage variable was calculated using the material constitutive equation, which included a damage evolution equation. An uncoupled damage analysis was restrictively performed between the fully-coupled analyses of stable regions of the damage evolution.

\subsection{Fully-Coupled Analysis: Damage-Coupled Constitutive Model}

In this study, the Bodner-Partom material model was employed as a material constitutive model for the computational fatigue crack growth rate evaluation of 7\% nickel steel [18]. This model is an elastic-viscoplastic model describing rate-dependent plasticity and creep. This means that material behavior is always being modeled as having a certain degree of inelasticity. Therefore, the Bodner-Partom material model is recognized as a unified viscoplastic model, because it can express the yield phenomenon of materials over a wide range of strain rates and temperatures quite effectively, despite the absence of yield functions. This distinguishing feature is intended so that the overall framework expressing the macroscopic response properties, such as strain rate sensitivity and temperature dependency, are consistent with the essential physics of elastic and inelastic deformation. Therefore, 
this model was developed in the form of macroscopic equations, and specific microscopic mechanisms were not necessary. The employed viscoplastic model is described as in the following [18].

$$
\begin{gathered}
\dot{\varepsilon}_{i j}=\dot{\varepsilon}_{i j}^{e}+\dot{\varepsilon}_{i j}^{P} \\
\dot{\varepsilon}_{i j}^{P}=D_{0} \exp \left[-\frac{1}{2}\left(\frac{Z}{\sigma_{e f f}}\right)^{2 n}\right] \frac{\sqrt{3} S_{i j}}{\sigma_{e f f}}
\end{gathered}
$$

where $\dot{\varepsilon}_{i j}, \dot{\varepsilon}_{i j}^{e}$ and $\dot{\varepsilon}_{i j}^{P}$ are the total strain, the elastic strain and the plastic strain rate tensor, respectively. $D_{0}$ is the assumed maximum plastic strain rate, $Z$ is the total hardening variable, and $n$ is the material parameter that controls the rate sensitivity. $\sigma_{\text {eff }}$ is the effective stress. The total hardening variable is defined as follows:

$$
\begin{gathered}
Z=Z_{1}-\left(Z_{1}-Z_{0}\right) \exp \left(-m_{h} W_{P}\right) \\
W_{P}=\int d W_{P}=\int \sigma_{i j} \mathrm{~d} \varepsilon_{i j}^{P}
\end{gathered}
$$

where $Z_{0}$ and $Z_{1}$ are the initial and saturated values of the isotropic hardening variable, respectively; $m_{h}$ is the rate of isotropic hardening; and $W_{P}$ is the plastic work. $\sigma_{i j}$ is the stress tensor.

Generally, a two-scale damage model is adopted for expressing material degradation under high-cycle fatigue loading [21,43-45]. The two-scale damage model is based on the notion that initiation and evolution of the damage in brittle fractures and high-cycle fatigue fractures are governed by plastic deformation in a microscopic region of a material [21]. A two-scale damage model includes a scale transition law that links the mesoscopic and microscopic scales. Therefore, a large number of experiments are required to define a scale transition law and determine the internal state variable in a microscopic region, such as accumulated plastic strain.

In this study, a Bodner-Chan damage model was used to express the material degradation and crack growth of 7\% nickel steel during the simulation of crack growth under high-cycle fatigue loading [18]. Instead of the two-scale damage model, rearrangement of the critical damage was adopted for the material degradation under high-cycle fatigue loading. As previously mentioned, the damage-coupled constitutive model employed in this study is always modeled as having a certain degree of plasticity. This feature is effective for expressing material failure under high-cycle fatigue. A scale for rearrangement of the critical damage was obtained from some simulations described in Section 4.2.

The viscoplastic model described above was incorporated in the damage model expressed below [18]:

$$
\begin{gathered}
\dot{\varepsilon}_{i j}^{P}=D_{0} \exp \left[-\frac{1}{2}\left(\frac{Z(1-\omega)}{\sigma_{e f f}}\right)^{2 n}\right] \frac{\sqrt{3} S_{i j}}{\sigma_{e f f}} \\
\dot{\omega}=\frac{b}{h}\left[\ln \left(\frac{1}{\omega}\right)\right]^{\frac{b+1}{b}} \omega \dot{\mathrm{Q}} \\
\dot{\mathrm{Q}}=\left(C_{1} \sigma_{\text {max }}^{+}+C_{2} \sigma_{\text {eff }}+C_{3} I_{1}^{+}\right)^{r}
\end{gathered}
$$


where $\omega$ is the damage parameter which is the material internal state variable and $S_{i j}$ is the deviatoric stress tensor. $b$ and $h$ are the material parameters that control the characteristics of damage, and $\dot{\mathrm{Q}}$ is the multiaxial stress function proposed by Hayhurst and Leckie [46]. $\sigma_{\max }^{+}, \sigma_{e f f}$, and $I_{1}^{+}$are the maximum tensile principal stress, effective stress, and first stress invariant, respectively. $C_{1}, C_{2}, C_{3}$ and $r$ are constants of the material, such that $C_{1}+C_{2}+C_{3}=1$.

\subsection{Uncoupled Analysis: Jump-in-Cycles Procedure}

In the present study, the jump-in-cycles procedure is adopted to calculate fatigue damage in order to reduce the computation time. This procedure can be classified with the uncoupled method in structural damage analysis [19]. The jump-in-cycles procedure is a method to "jump" full blocks of $\overline{\Delta N}$ cycles in a damage calculation based on the postulation that damage accumulation is progressed linearly in the stable region of damage accumulation. $\overline{\Delta N}$ is expressed as follows:

$$
\overline{\Delta N}=\frac{\overline{\Delta \omega}}{\left.\frac{\delta \omega}{\delta N}\right|_{N_{S}}}
$$

where $\overline{\Delta N}$ is the blocks of number of cycles, and $\overline{\Delta \omega}$ is the accumulated damage for the jumped blocks. $\overline{\Delta \omega}$ is also a given value that determines the accuracy of the procedure. $\overline{\Delta \omega} \approx \omega_{c r} / 50\left(\omega_{c r}\right.$ is the critical damage) is a good compromise between accuracy and time cost [19]. $N_{\mathrm{S}}$ is a stabilized cycle, and $\left.\frac{\delta \omega}{\delta N}\right|_{N_{S}}$ is the accumulated damage increment over this single cycle. The accumulated damage is updated as

$$
\omega\left(N_{S}+\overline{\Delta N}\right)=\omega\left(N_{S}\right)+\left.\frac{\delta \omega}{\delta N}\right|_{N_{S}} \overline{\Delta N}
$$

\subsection{Algorithm for Computational FCGR Tests}

As mentioned previously, computational method for FCGR tests based on damage-coupled FEA is comprised of fully coupled and uncoupled approaches coped with material constitutive model and jump-in-cycles procedure, respectively. Each of procedures for analysis was implemented into ABAQUS user defined subroutine UMAT and algorithm for mutual calculation of damage accumulation from fully and uncoupled analyses was carried out. UMAT is well known that the commercial FE code ABAQUS allows the definition of the material state at every integration point within the FE element. In this regard, the ABAQUS user-defined subroutine UMAT is commonly used to implement a specific constitutive model in the finite element analysis. This can give a significant improvement in the FE analysis results, especially if there is no adequate material model within the ABAQUS libraries.

Figure 7 shows a schematic of the accumulated damage during the fatigue analysis using the proposed method comprised of the fully and uncoupled damage analyses (hereafter referred to as the "hybrid method"). First, the fatigue damage was calculated using the fully coupled approach (using the damage-coupled material constitutive model). This process was relevant to the section from point A to point B in Figure 7. If the damage accumulation calculated by the damage-coupled material constitutive model was stable at 
point $\mathrm{B}$, the jump-in-cycles procedure was conducted, and the accumulated damage was updated as point $\mathrm{C}$, as follows:

$$
\omega_{\mathrm{B}}=\omega_{\mathrm{A}}+\Delta \omega_{\mathrm{JICint}}
$$

where $\Delta \omega_{\text {JICint }}$ is the accumulated damage during jump-in-cycles procedure and $\Delta \omega_{\text {JICint }}$ is calculated by

$$
\Delta \omega_{\text {JICint }}=\left.\frac{\delta \omega}{\delta N}\right|_{N_{S}} \Delta N_{\text {JICint }}
$$

where $\Delta N_{\text {JICint }}$ is the jumped blocks of number of cycles for the accumulation of damage updated by the jump-in-cycles procedure. In other words, $\Delta N_{\text {JICint }}$ is the saved computation time (number of cycles) for the fatigue damage analysis. This uncoupled approach to the damage analysis is relevant to the section from point $B$ to point $C$ shown in Figure 7. Subsequently, the time increment is shifted to point $C^{\prime}$ from point $C$, and the uncoupled process is terminated. As shown in Figure $7, \Delta t_{C C^{\prime}}$ is the shifted time increment that resulted from the jump-in-cycles procedure, and this parameter is the other value along with $\Delta N_{\text {JICint }}$. This was because the fatigue damage analysis was performed in the real-time domain rather than using the number of cycles. In this study, the adopted damage-coupled constitutive model was formulated based on the real-time domain. $\Delta N_{\text {JICint }}$ and $\Delta t_{C C^{\prime}}$ represented the saved number of cycles and saved time increments, respectively. When a $\Delta N_{\text {JICint }}$ value obtained from the jump-in-cycles procedure was 1000 cycles, there was a $100 \mathrm{~s}$ time increment shift in the structural analysis (assuming a time increment of $0.1 \mathrm{~s}$ was required for the structural analysis for a 1-cycle load). Finally, in the section from point $C^{\prime}$ to point $\mathrm{D}$, the fatigue damage was again calculated based on the damage-coupled material constitutive model. The systematic process for fatigue damage analysis proposed here can be briefly summarized as follows: (1) fully coupled analysis; (2) uncoupled analysis; (3) increment shift; and (4) fully coupled analysis again.

In the present study, the parameter $\Delta N_{\text {JICint }}$ was predetermined to calculate the accumulated damage by the jump-in-cycles procedure because the ratio of the accumulated damage increment and the increment in the number of cycles in the stable region $\left.\frac{\Delta \omega}{\Delta N}\right|_{N_{S}}$ was difficult to obtain numerically. Therefore, $\Delta N_{\text {JICint }}$ and $\left.\frac{\Delta \omega}{\Delta N}\right|_{N_{S}}$ were predetermined, and the value of $\Delta \omega_{\text {JICint }}$ was checked using $\omega_{c r} / 50$. In the present study, $\Delta N_{\text {JICint }}$ values of 1000 and 10,000 cycles were used at room and cryogenic temperatures, respectively. The increment used for the number of cycles in the stable region $\left.\Delta N\right|_{N_{S}}$ was 100 cycles for both temperatures. It was postulated that the stable regions appeared when the accumulated damage reached $1.0 \times 10^{-10}$ and $1.0 \times 10^{-20}$ in the room and cryogenic temperature cases, respectively. 


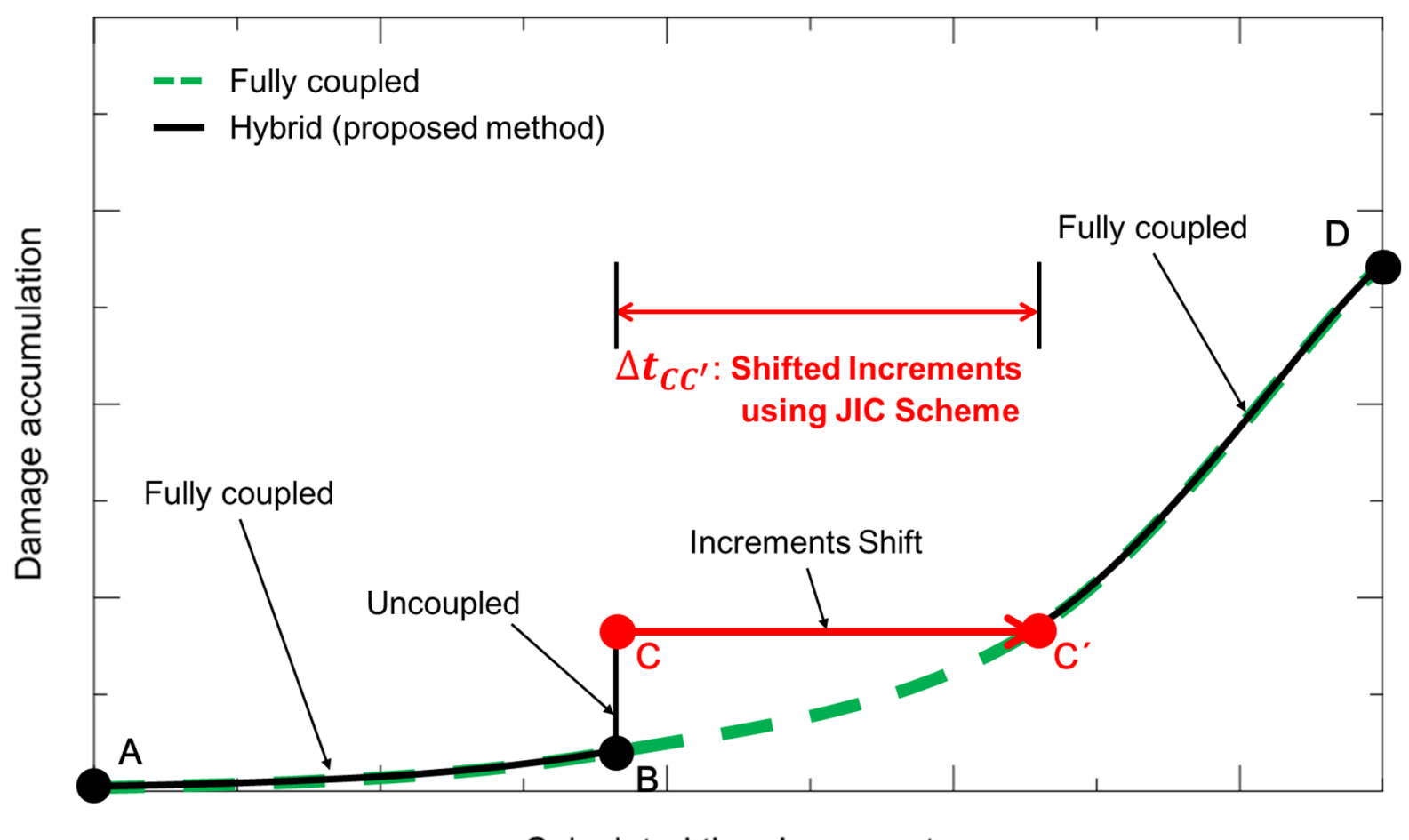

Calculated time increments

Figure 7. Schematic of accumulated damage under fatigue analysis using proposed method comprised with fully and uncoupled damage analysis approaches.

The aforementioned process for calculating the accumulated damage using jump-in-cycles procedure was implemented into ABAQUS user defined subroutine UMAT and damage-coupled material constitutive model classified as a fully coupled approach was also implemented into ABAQUS UMAT. The computational algorithm of UMAT for FCGR test simulation is presented in Figure 8. The most of times for structural damage analysis is carried out using the fully coupled method based on a damage-coupled constitutive model. The jump-in-cycles procedure is used as an uncoupled method for reducing the computation time. The jump-in-cycles procedure for damage analysis was already adopted in the author's previous study and was verified for calculating the high cycle fatigue damage, although fatigue analyses were carried out using PATRAN/NASTRAN [17].

The implicit formulation of the damage-coupled constitutive model is also carried out and implemented into ABAQUS UMAT. All of these incremental values and the damage parameter $\omega$ must be updated in the calculation procedure by the definition of the solution-dependent state variables (SDVs). SDVs are initialized in the subroutine SDVINI of ABAQUS. The value of $\omega$ progressively increases, and the subroutine FAILURE is called to reduce the corresponding element stiffness when $\omega$ reaches the predetermined critical value $\omega_{\text {cr. }}$. 


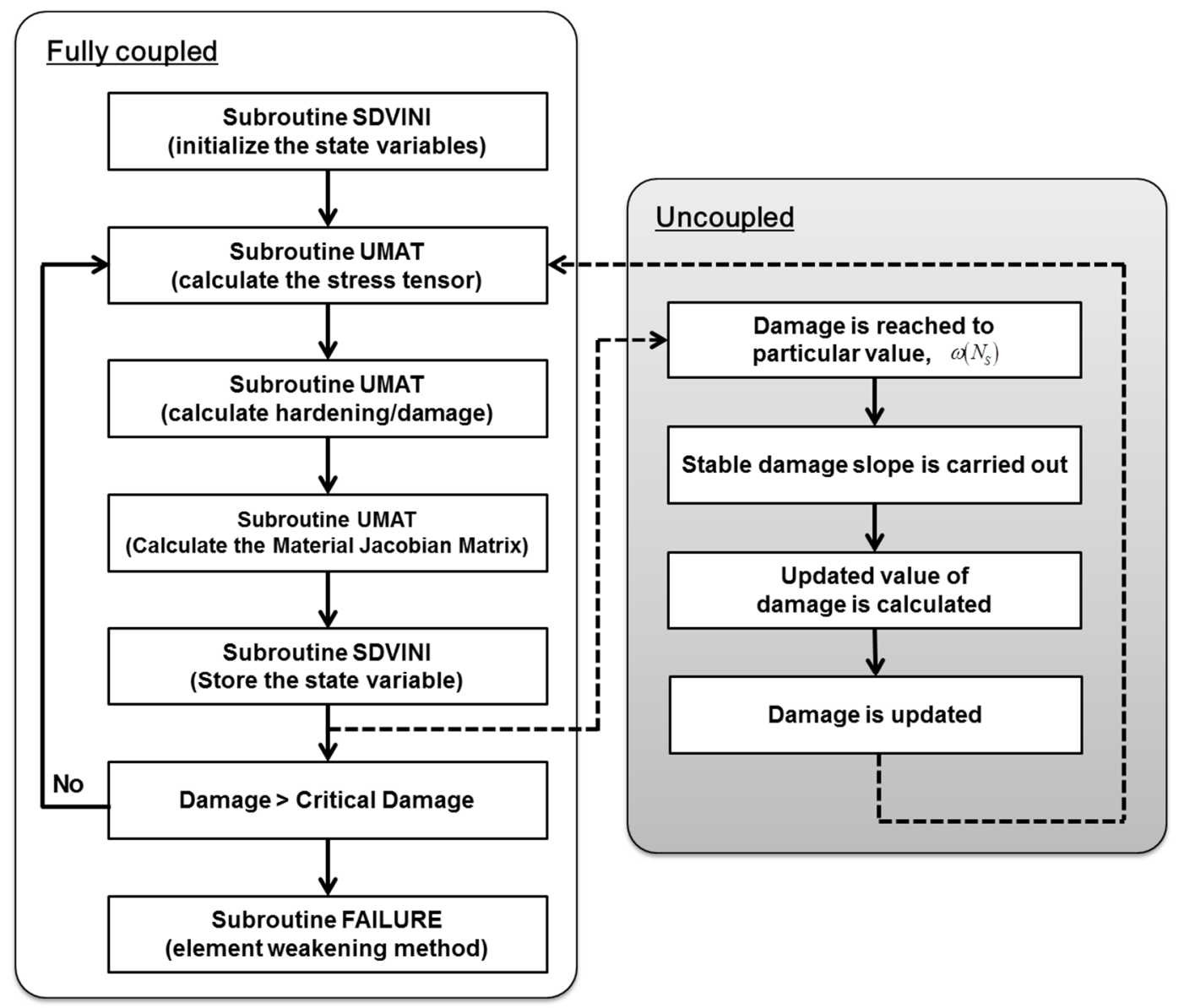

Figure 8. Computational algorithm of UMAT for FCGR test simulation.

The optimal time increment $\Delta t$ and the corresponding strain increment, which are computed at the end of the previous time increment, are determined using the Jacobian matrix. The numerical integration scheme used in the present study is described below. The incremental strain is given by

$$
\Delta \varepsilon_{i j}=\varepsilon_{i j}^{n+1}-\varepsilon_{i j}^{n}
$$

The corresponding elastic trial stress tensor is computed from

$$
\sigma_{i j}^{n+1(\text { trial })}=\sigma_{i j}^{n}+D_{i j k l} \Delta \varepsilon_{k l}
$$

where $D_{i j k l}$ is the elastic stiffness tensor. The updates of the stresses can then be obtained from

$$
\sigma_{i j}^{n+1}=\sigma_{i j}^{n+1(\text { trial })}-\Delta \lambda D_{i j k l} S_{k l}^{n+1}
$$

where $\lambda$ is the plastic multiplier. The scalar $\Delta \lambda$, defined by $\Delta \lambda=\lambda \Delta t$, can be calculated on the basis of the damage using

$$
\Delta \lambda=\sqrt{\frac{D_{0}^{2}}{J_{2}} \exp \left[-\left(\frac{Z^{2}(1-\omega)^{2}}{3 J_{2}}\right)^{n}\right]} \Delta t
$$

At the end of the increment, the time history values of each solution-dependent state variable are stored using the STATEV array. The following equations are representative state variables of the constitutive equation: 


$$
\begin{gathered}
Z_{n+1}=Z_{n}+\Delta \lambda m\left[Z_{1}-Z^{I}\right] 2 J_{2} \\
\omega_{n+1}=\omega_{n}+\frac{b}{h}\left[\ln \left(\frac{1}{\omega}\right)\right]^{\frac{b+1}{b}} \omega \dot{\mathrm{Q}} \Delta t
\end{gathered}
$$

\section{Computational FCGR Tests}

\subsection{Simulation of Uniaxial Tensile Tests and Determination of Material Parameters}

Simulations of uniaxial tensile tests for $7 \%$ nickel steel are performed at room and cryogenic $\left(-163{ }^{\circ} \mathrm{C}\right)$ temperatures in order to verify the developed UMAT and determine the material parameters for computational FCGR tests. The jump-in-cycles procedure is not considered during the simulation of tensile tests for $7 \%$ nickel steel. The material parameters of the aforementioned damage-coupled constitutive model for $7 \%$ nickel steel are determined by a comparison of the results, presented as the stress-strain relationship, between the simulation and the experiments. The determined material parameters for $7 \%$ nickel steel at room and cryogenic temperatures are employed for the computational FCGR tests. Among the material parameters, the critical damage $\left(\omega_{c r}\right)$ is rearranged for fatigue damage analysis. The FE model for simulation of uniaxial tensile tests of 7\% nickel steel is adopted from author's previous study and sensitivity of mesh size is also analyzed [38]. A rod-type FE model was controlled in the $y$-direction and strain rate applied to the specimen is $1.0 \times 10^{-4} / \mathrm{s}$ for both temperatures. As can be observed from the Figure 9, the developed UMAT could describe the stress-strain relationship of 7\% nickel steel for both the room and the cryogenic temperatures. The material parameters of the computational FCGR tests are summarized in Table 4.

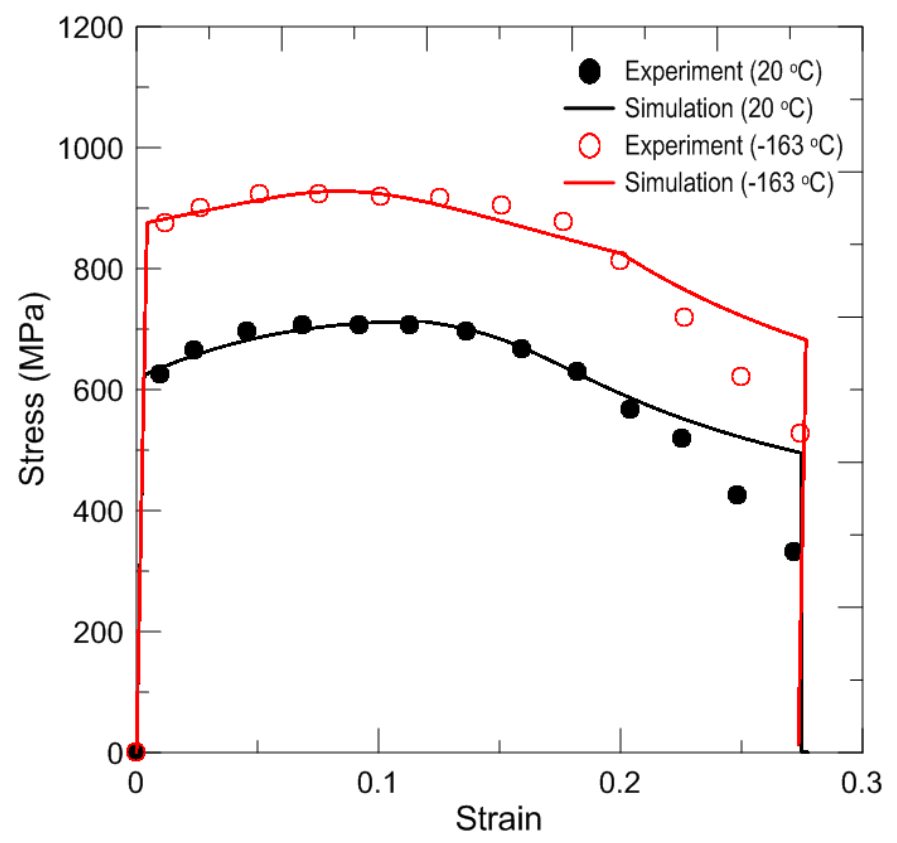

Figure 9. Comparison of uniaxial tensile tests of $7 \%$ nickel steel. 
Table 4. Material parameters of damage-coupled constitutive model for computational fatigue crack growth rate tests.

\begin{tabular}{|c|c|c|c|c|c|c|}
\hline \multirow{4}{*}{$\begin{array}{c}\text { Room } \\
\text { Temperature } \\
\left(20^{\circ} \mathrm{C}\right)\end{array}$} & $E(\mathrm{GPa})$ & $v$ & $Z_{0}(\mathrm{MPa})$ & $Z_{1}$ (MPa) & $D_{0}\left(\mathrm{~s}^{-1}\right)$ & $m$ \\
\hline & 203 & 0.33 & 1450 & 1380 & 1.0 & 0.025 \\
\hline & $n$ & $b$ & \multicolumn{2}{|c|}{$h$} & $r$ & $\omega_{c r}$ \\
\hline & 2.05 & 4.28 & \multicolumn{2}{|c|}{$7.25 \times 10^{18}$} & 5.50 & 0.20 \\
\hline \multirow{4}{*}{$\begin{array}{c}\text { Cryogenic } \\
\text { Temperature } \\
\left(-163^{\circ} \mathrm{C}\right)\end{array}$} & $E(\mathrm{GPa})$ & $v$ & $Z_{0}(\mathrm{MPa})$ & $Z_{1}(\mathrm{MPa})$ & $D_{0}\left(\mathrm{~s}^{-1}\right)$ & $m$ \\
\hline & 203 & 0.33 & 1650 & 1600 & 1.0 & 0.003 \\
\hline & $n$ & $b$ & \multicolumn{2}{|c|}{$h$} & $r$ & $\omega_{c r}$ \\
\hline & 4.30 & 1.00 & \multicolumn{2}{|c|}{$1.63 \times 10^{19}$} & 5.50 & 0.20 \\
\hline
\end{tabular}

\subsection{Rearrangement of Critical Damage $\left(\omega_{c r}\right)$ and Fatigue Precrack Simulation}

As mentioned previously, a numerical approach instead of theoretical approach using a two-scale damage model for fatigue damage analysis is carried out in the present study. Critical damage $\left(\omega_{c r}\right)$ is rearranged, and fatigue precrack simulations adapting rearranged critical damage are performed at room temperature. The jump-in-cycles procedure is not considered during the fatigue precrack simulation.

The material parameters for the damage-coupled constitutive model, which are implemented into UMAT, are employed from the simulation of the material tension test at room temperature, and the rearranged values of the critical damage are also employed for the computational fatigue precrack test.

Figure 10 shows an FE model of the FCGR test specimen, which is used to perform simulations. A compact tension (CT) type specimen of the FE model is composed of 6285 elements (8 node-reduced integral elements, C3D8R in ABAQUS, using the same element type as the FE model for tension test simulation) and 8052 nodes. The crack tip radius of the FE model is $1 \mathrm{~mm}$. The minimum element length is also $1 \mathrm{~mm}$ near the crack tip line. The problem of mesh size sensitivity for a stable solution, with regard to the simulation of crack propagation, was investigated in the authors' previous study [36]. The suitable minimum element length in the case of a $1-\mathrm{mm}$ crack tip radius was carried out as $0.1 \mathrm{~mm}$, although a minimum element length of $1.0 \mathrm{~mm}$ is employed in this study to save calculation time costs. Moreover, computational fatigue precracking, including the $K$-decreasing procedure, is performed in the same way as experimental precracking at room temperature in the present study. The load history according to the $K$-decreasing procedure was obtained from the data resulting from the experimental fatigue precrack test and was employed as a loading condition of the precracking simulation (see Figure 2). As shown in Figure 10, the red-outlined sections for the upper and lower holes were similarly controlled using MPC in the experimental tests. The lower hole was restrained in the $x$-, $y$-, and $z$-directions. The upper hole was restrained in the $x$ - and $z$-directions and was applied cyclic loading.

In this study, the rearranged value of critical damage is assigned a value $\omega^{*}$, and the rearranged values are considered as $\omega_{c r}, \omega_{c r} / 100$ and $\omega_{c r} / 10,000$. Figure 11 shows a comparison between the experiment and the simulation of the relationships between the crack length and the number of cycles from the fatigue precrack test, adopting each of rearranged critical damage. The effective stress contour at 27,374 cycles (the number of cycles at which the fatigue precrack test was terminated) adopting $\omega_{c r}^{*}=\omega_{c r} / 10,000$ is also shown in Figure 11. Although there are some discrepancies between the results, it is found that rearrangement of $\omega^{*}{ }_{c r}=\omega_{c r} / 10,000$ is sufficient to perform the fatigue crack 
damage analysis. Rearranged critical damage was adopted to the material parameters for each FCGR test simulation at room and cryogenic temperatures. In addition, the accumulated damage values of each damaged element from the fatigue precrack simulation are adopted for the main FCGR test simulation as the initial accumulated damage of the FE specimen at both the room and the cryogenic temperatures.
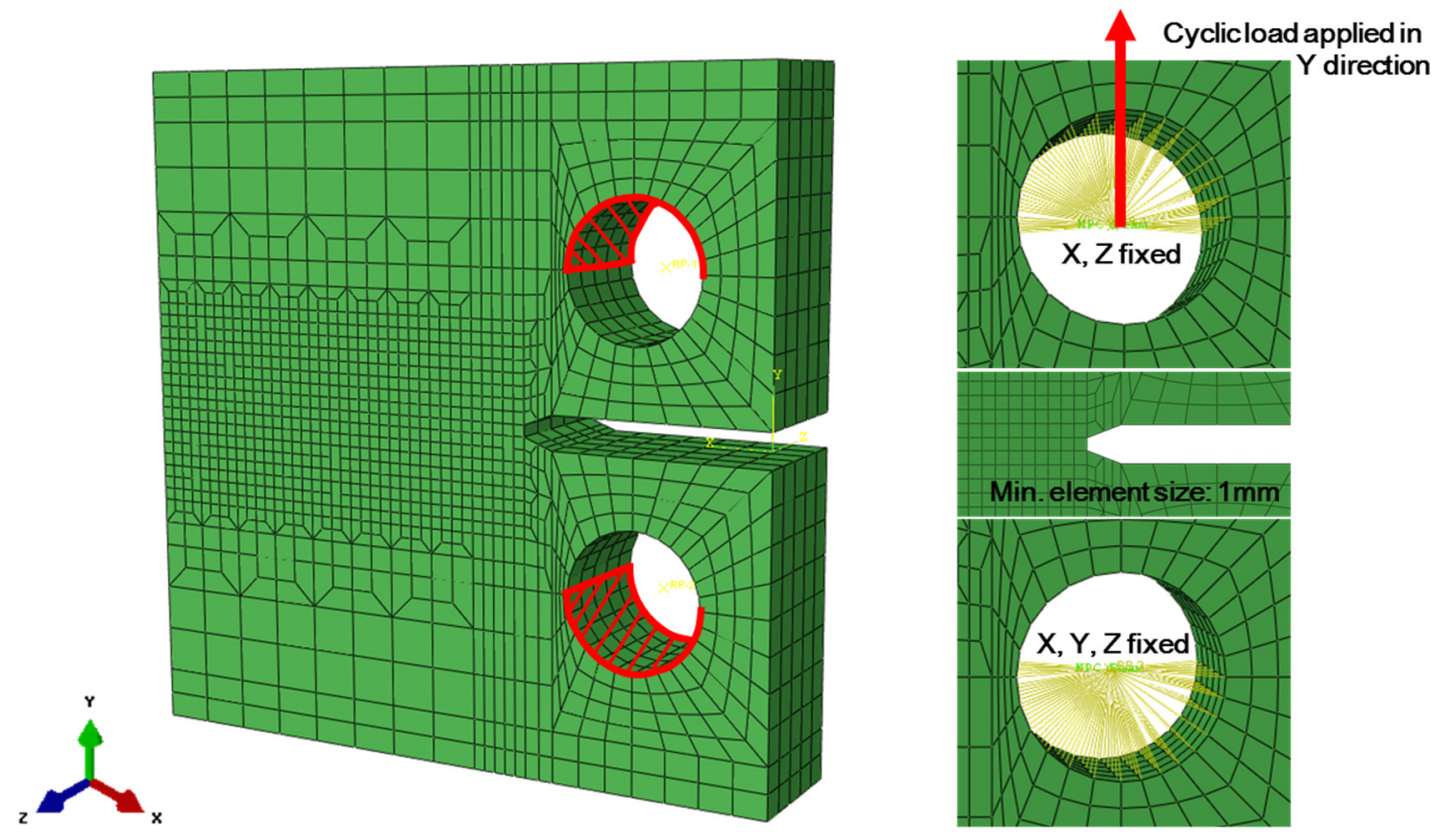

Figure 10. Finite element (FE) model of compact tension (CT) specimen for ABAQUS.
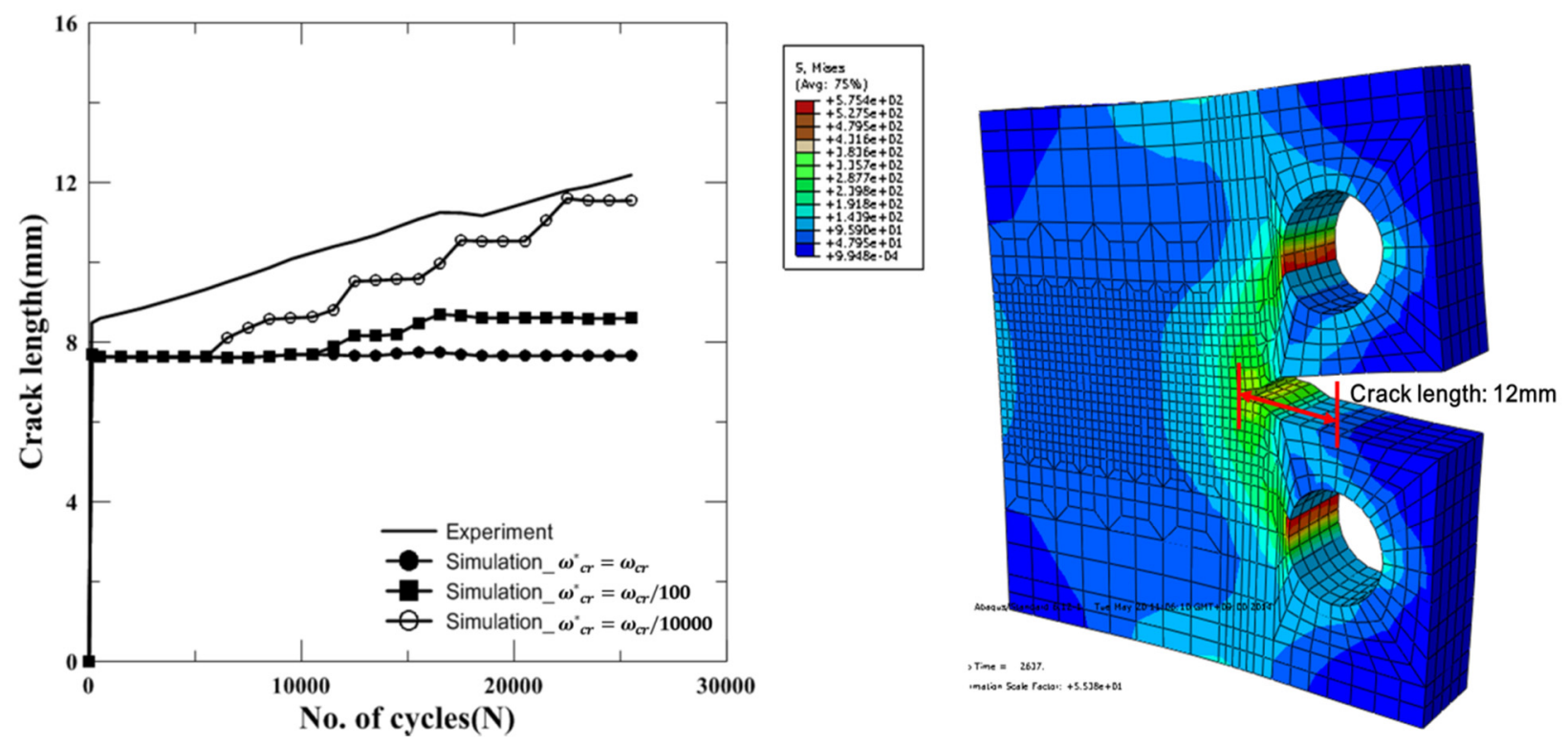

Figure 11. Comparison of relationships between the crack length and the number of cycles obtained from experimental fatigue precrack test and simulation according to varied critical damage (left) and the effective stress contour after precrack simulation (right). 


\subsection{Main Test Simulation}

The developed ABAQUS UMAT, including the jump-in-cycles procedure, is adopted for computational FCGR tests of 7\% nickel steel at room and cryogenic temperatures. Rearranged critical damage is also adopted in order to consider calculate the fatigue damage resulting from the fatigue precrack simulations. The FE model of CT specimen for the main test is the same as model for the fatigue precrack simulation. The loading conditions of the main tests at room and cryogenic temperatures are the same. As shown in Figure 10, the red-outlined sections for the upper and lower holes were similarly controlled using MPC in the experimental tests. The lower hole was restrained in the $x$-, $y$-, and $z$-directions, and the upper hole was restrained in the $x$ - and $z$-directions. In the $y$-direction, cyclic loading was applied which has $18 \mathrm{kN}$ and $0 \mathrm{kN}$ of maximum and minimum load levels, respectively, and the load frequency of cyclic loading is $10 \mathrm{~Hz}$. The crack length value increases during the simulation are measured according to intuition, in contrast with the compliance method adopted for the experimental estimation.

Representative simulation results are shown in Figure 12 for comparison with the experimental results. Figure 12 shows a comparison of the relationships between the crack lengths and number of cycles obtained from the experimental results and the numerical estimations. While computational evaluation is terminated when the crack length is approximately $30 \mathrm{~mm}$, it can be observed that the crack growth rate under fatigue loading was sufficiently simulated numerically.
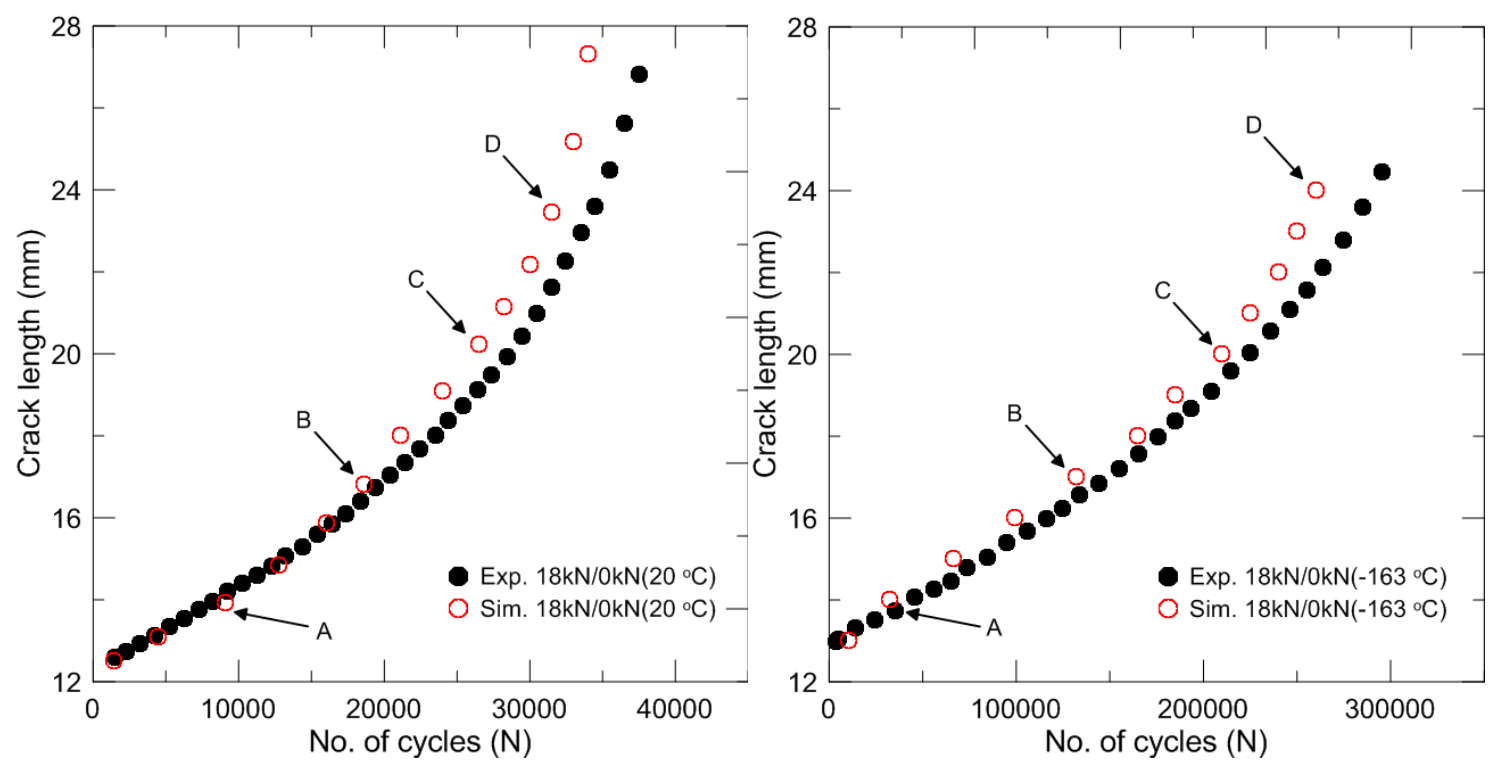

Figure 12. Relationships between the crack length and the number of cycles at room (left) and cryogenic (right) temperatures.

Figure 13 shows the crack propagations of the CT specimen corresponding to each point in Figure 12 at both temperatures. It can be observed that the crack propagation along the crack tip was sufficiently simulated numerically. 

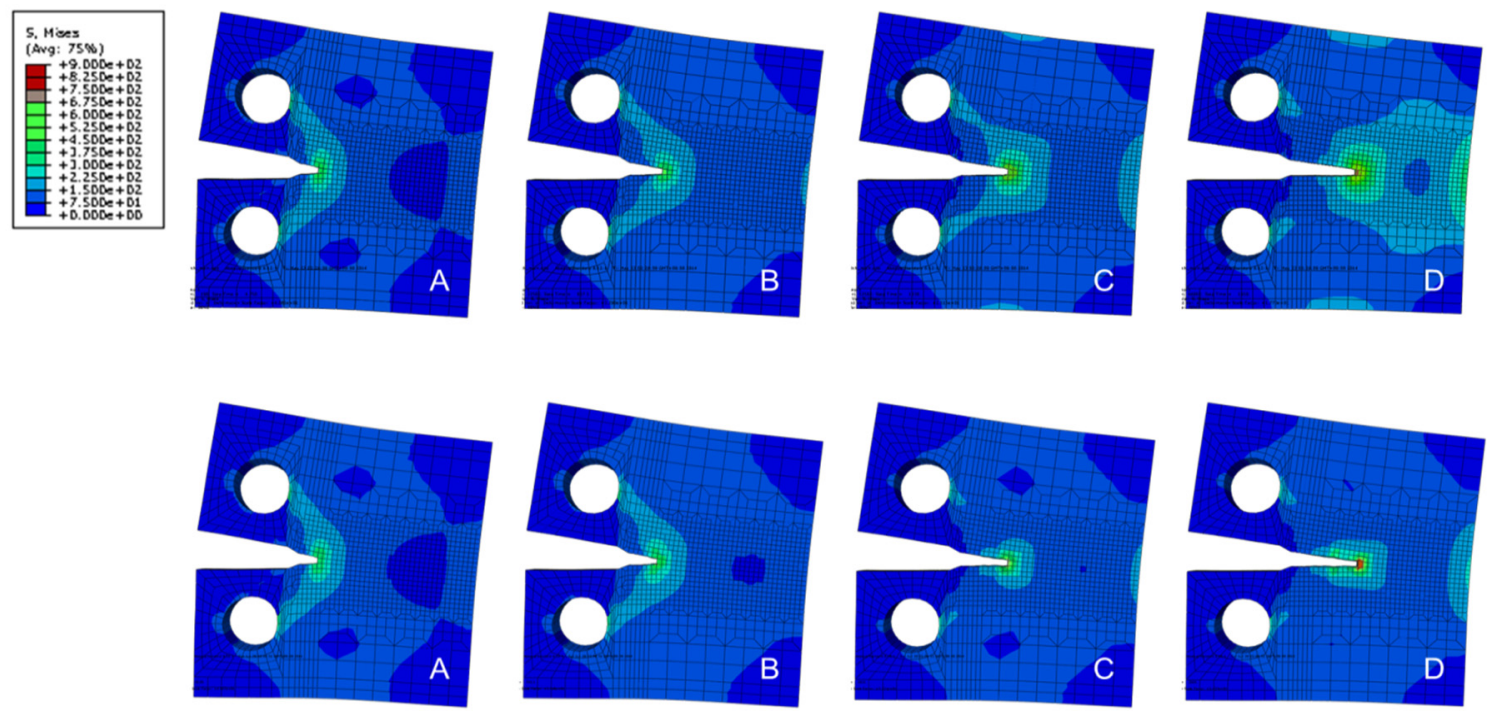

Figure 13. Crack propagations of specimen at room (upper) and cryogenic (bottom) temperatures.

Figure 14 shows a comparison of the relationship between $\mathrm{d} a / \mathrm{d} N$ and $\Delta K$ obtained from the experimental and the numerical estimation. The constants of Paris' law, $C$ and $m$, carried out from each test are summarized in Table 5. In this study, a systematic approach involving the following steps was used to perform a computational fatigue crack growth rate test: (1) selection of proper constitutive and damage models; (2) comparison of the experimental results with those of typical material testing (e.g., uniaxial tension); and (3) development of a user subroutine and its application to an actual case. For simulation of fatigue crack growth, the procedure for reducing the calculation time (the jump-in-cycles procedure) and the numerical approach (rearrangement of critical damage) are adopted and are implemented to user subroutine. If the adopted constitutive and damage models sufficiently describe the material characteristics and the suitable procedure and rearrangement are employed, this approach can maximize the effectiveness of a user-friendly environment in the commercial FEA code.
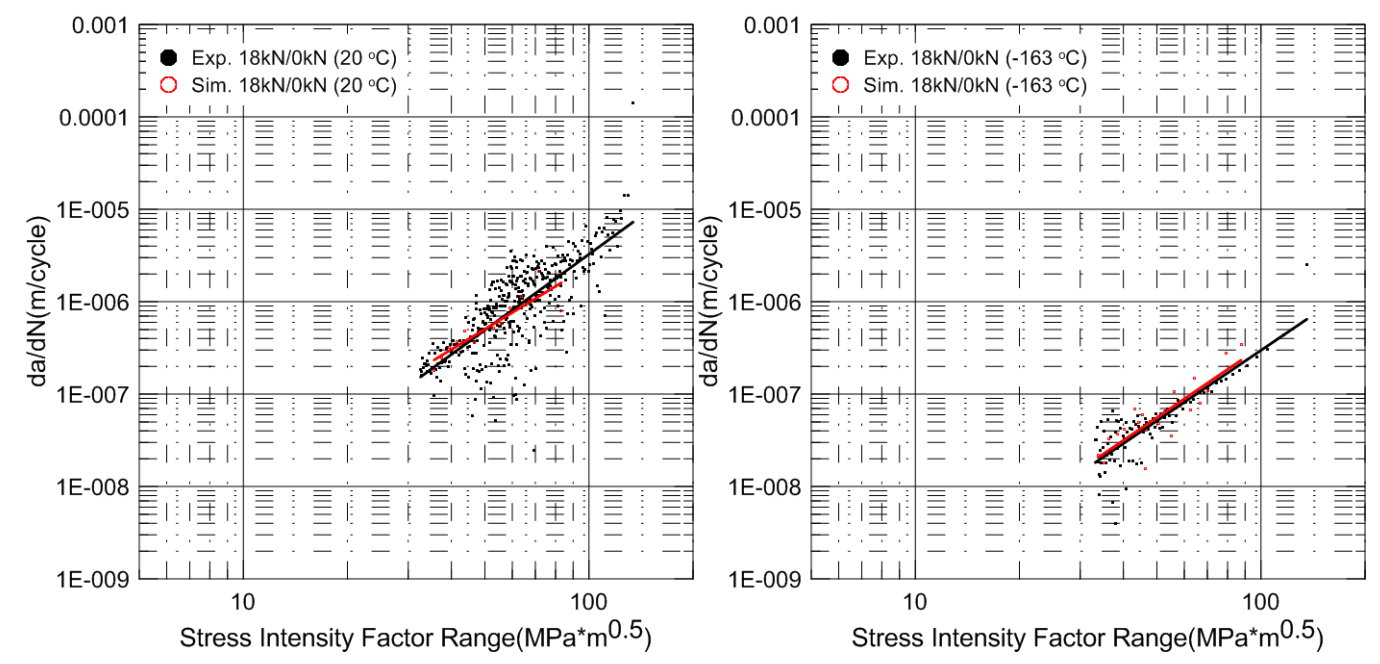

Figure 14. Relationship between $\mathrm{d} a / \mathrm{d} N$ and $\Delta K$ at room (left) and cryogenic (right) temperatures. 
Table 5. Paris' law constants obtained from experiments and simulations.

\begin{tabular}{ccccc}
\hline Specimen Type & Temperature $\left({ }^{\circ} \mathbf{C}\right)$ & Method & $\boldsymbol{C}$ & $\boldsymbol{m}$ \\
\hline \multirow{3}{*}{$\begin{array}{c}\text { Compact } \\
\text { Tension }\end{array}$} & \multirow{2}{*}{20} & Experiment & $2.17 \times 10^{-11}$ & 2.57 \\
\cline { 2 - 5 } & & Simulation & $7.05 \times 10^{-11}$ & 2.27 \\
\cline { 2 - 5 } & \multirow{2}{*}{-163} & Experiment & $1.61 \times 10^{-12}$ & 2.71 \\
\cline { 2 - 5 } & & Simulation & $1.50 \times 10^{-11}$ & 2.10 \\
\hline
\end{tabular}

\section{Conclusions}

In the present study, the fatigue crack growth rates (FCGRs) of 7\% nickel steel are computationally evaluated at room and cryogenic temperatures. The computational FCGR test was carried out using a damage-coupled material constitutive model, which was implemented to the ABAQUS user-defined subroutine, UMAT, for application in the FEA environments. To perform the fatigue damage analysis, the jump-in-cycles procedure and a numerical approach of rearranging critical damage are employed and implemented to the ABAQUS UMAT. The results obtained by the numerical simulation were compared with the experimental results. Some key aspects of the results are highlighted below:

- A set of values for Paris' law constants of 7\% nickel steel, which has been recently applied in LNG carrier storage systems, were obtained at room and cryogenic $\left(-163{ }^{\circ} \mathrm{C}\right)$ temperatures. For a compact tension (CT) specimen under tension-type (maximum load: $18 \mathrm{kN}$, minimum load: $0 \mathrm{kN}$, stress ratio: 0 ) cyclic loading, the Paris' law constants $C$ and $m$ were $2.17 \times 10^{-11}$ and 2.57 at room temperature and $1.61 \times 10^{-12}$ and 2.71 at cryogenic temperature, respectively.

- It was observed that typical results of the experimental FCGR tests (for Paris' law constants and the relationship between the crack length and the number of cycles) could be obtained numerically. A comparison with the experimental results revealed that the correct use of a damage-coupled material constitutive model and approaches for fatigue damage analysis produces satisfactory results.

- A computational approach incorporating a material constitutive model, the jump-in-cycles procedure, and the rearrangement of critical damage was proposed. The proposed procedure offers useful fatigue crack growth solutions to a designer, particularly when experimental measurement is extremely difficult or unavailable.

\section{Acknowledgments}

This work was supported by a National Research Foundation of Korea (NRF) grant funded by the Korean government (MSIP) through GCRC-SOP (No. 2011-0030013). This research was also supported by the Basic Science Research Program funded by the Ministry of Education (No. 2013R1A1A2A10011206) through the National Research Foundation of Korea (NRF).

\section{Author Contributions}

Seul-Kee Kim is the first author of the paper and performed the FCGR simulations. Chi-Seung Lee and Jeong-Hyeon Kim aided in the description of the material constitutive model and implementation into FEA. Myung-Hyun Kim aided in the performance and analysis of the experimental FCGR tests. Byeong-Jae Noh and Toshyuki Matsumoto aided in the review of the paper and provided critical 
comments. Jae-Myung Lee is the corresponding author of the paper, and conceived the paper and supervised the theoretical and numerical processes described in the paper.

\section{Nomenclature}

$a$ : Crack length

$\alpha$ : The ratio between crack length and width of specimen

B: Thickness of compact tension type specimen

$b$ : Material parameter that control the characteristics of damage

$C$ : Constants of Paris's law

$C_{1} \sim C_{3}$ : Material constants in multiaxial stress function

$C_{a} \sim C_{f}$. Constants determined from the measuring location as shown in Figure 4

$D_{0}$ : Assumed maximum plastic strain rate

$D_{i j k l}$ : Elastic stiffness tensor

$\Delta K$ : Stress intensity factor range

$\Delta N_{\text {JICint }}$ : Jumped blocks of number of cycles during jump-in-cycles procedure

$\Delta \omega_{\text {JICint }}:$ Accumulated damage during jump-in-cycles procedure

E: Elastic modulus

$\dot{\varepsilon}_{i j}:$ Total strain rate tensor

$\dot{\varepsilon}_{i j}^{e}$ : Elastic strain rate tensor

$\dot{\varepsilon}_{i j}^{p}$ : Plastic strain rate tensor

$G_{\text {IC: }}$ Strain energy release rate

$h$ : Material parameter that control the characteristics of damage

$I_{1}^{+}$: First stress invariant

$J_{2}$ : Second stress invariant

$K_{\max }$ : Maximum stress intensity factor

$\lambda$ : Plastic multiplier

$m$ : Constants of Paris's law

$m_{h}$ : Rate of isotropic hardening

$N$ : Number of cycle

$n$ : Material parameter that controls the rate sensitivity

$N_{\mathrm{S}}$ : Stabilized cycle of damage accumulation

$\omega$ : Damage parameter

$\omega_{\text {cr: }}$ Critical damage

$\omega^{*}{ }_{c r}$ : Rearranged critical damage

P: Force

$\dot{\mathrm{Q}}$ : Multiaxial stress function

$r$ : Material constants in multiaxial stress function

$S_{i j}$ : Deviatoric stress tensor

$\sigma_{\text {eff }}:$ Effective stress

$\sigma_{i j}:$ Stress tensor 
$\sigma_{\max }^{+}:$Maximum tensile principal stress

$t$ : Time

v: Displacement between the measurement points, as shown in Figure 4

$W$ : Width of compact tension type specimen

$W_{\mathrm{P}}$ : Plastic work

$Z$ : Total hardening variable

$Z_{0}$ : Initial isotropic hardening variable

$Z_{1}$ : Saturated isotropic hardening variable

\section{Conflicts of Interest}

The authors declare no conflict of interest.

\section{References}

1. Anderson, T.L. Fracture Mechanics, 3rd ed.; Taylor \& Francis: New York, NY, USA, 2005.

2. Paris, P.; Gomez, M.; Anderson, W.A. A rational analytic theory of fatigue. Trend Eng. 1961, 13, 9-14.

3. Elices, M.; Guinea, G.V.; Gomez, J.; Planas, J. The cohesive zone model: Advantages, limitations and challenges. Eng. Fract. Mech. 2002, 69, 137-163.

4. De-Andres, A.; Perez, J.L.; Ortiz, M. Elastoplastic finite element analysis of three-dimensional fatigue crack growth in aluminum shafts subjected to axial loading. Int. J. Solids Struct. 1999, 36, 2231-2258.

5. Yang, B.; Mall, S.; Ravi-Chandar, K. A cohesive zone model for fatigue crack growth in quasibrittle materials. Int. J. Solids Struct. 2001, 38, 3927-3944.

6. Roe, K.L.; Siegmund, T. An irreversible cohesive zone model for interface fatigue crack growth simulation. Eng. Fract. Mech. 2003, 70, 209-232.

7. Bouvard, J.L.; Chaboche, J.L.; Feyel, F.; Gallerneau, F. A cohesive zone model for fatigue and creep-fatigue crack growth in single crystal superalloys. Int. J. Fatigue 2009, 31, 868-879.

8. Ural, A.; Krishnan, V.R.; Papoulia, K.D. A cohesive zone model for fatigue crack growth allowing for crack retardation. Int. J. Solids Struct. 2009, 46, 2453-2462.

9. Moes, N.; Dolbow, J.; Belytschko, T. A finite element method for crack growth without remeshing. Int. J. Numer. Methods Eng. 1999, 46, 131-150.

10. Stolarska, M.; Chopp, D.L.; Moes, N.; Belytschko, T. Modelling crack growth by level sets in the extended finite element method. Int. J. Numer. Methods Eng. 2001, 51, 943-960.

11. Sukumar, N.; Chopp, D.L.; Moran, B. Extended finite element method and fast marching method for three-dimensional fatigue crack propagation. Eng. Fract. Mech. 2003, 70, 29-48.

12. Shi, J.; Chopp, D.; Lua, J.; Sukumar, N.; Belytschko, T. Abaqus implementation of extended finite element method using a level set representation for three-dimensional fatigue crack growth and life predictions. Eng. Fract. Mech. 2010, 77, 2840-2863.

13. Lemaitre, J. A continuous damage mechanics model for ductile fracture. J. Eng. Mater. Technol. Trans. ASME 1985, 107, 83-89.

14. Lemaitre, J. Micro-mechanics of crack initiation. Int. J. Fract. 1990, 42, 87-99. 
15. Chaboche, J.L. Continuum damage mechanics: Part II-Damage growth, crack initiation, and crack growth. J. Appl. Mech. 1988, 55, 65-72.

16. Chow, C.L. A damage mechanics model of fatigue crack initiation in notched plates. Theor. Appl. Fract. Mech. 1991, 16, 123-133.

17. Lee, C.S.; Kim, M.H.; Lee, J.M.; Mahendran, M. Computational study on the fatigue behavior of welded structures. Int. J. Damage Mech. 2011, 20, 423-463.

18. Bodner, S.R. Unified Plasticity for Engineering Applications, 1st ed.; Kluwer Academic and Plenum Publishers: New York, NY, USA, 2002.

19. Lemaitre, J.; Desmorat, R. Engineering Damage Mechanics, 1st ed.; Springer: Berlin, Germany, 2005.

20. Murakami, S. Continuum Damage Mechanics, 1st ed.; Springer: Berlin, Germany, 2012.

21. Lemaitre, J. A Course on Damage Mechanics, 2nd ed.; Springer: Berlin, Germany, 1992.

22. Gurson, A.L. Continuum theory of ductile rupture by void nucleation and growth: Part I-Yield criteria and flow rules for porous ductile media. J. Eng. Mater. Technol. Trans. ASME 1977, 99, $2-15$.

23. Tvergaard, V.; Needleman, A. Analysis of the cup-cone fracture in a round tensile bar. Acta Metall. 1984, 32, 157-169.

24. Chaboche, J.L. Constitutive equations for cyclic plasticity and cyclic viscoplasticity. Int. J. Plast. 1989, 5, 247-302.

25. Lemaitre, J.; Chaboche, J.L. Mechanics of Solid Materials, 1st ed.; Cambridge University Press: Cambridge, UK, 1990.

26. Ohno, N.; Wang, J.D. Kinematic hardening rules for simulation of ratchetting behavior. Eur. J. Mech. A-Solids 1994, 13, 519-531.

27. Hamon, F.; Henaff, G.; Halm, D.; Gueguen, M.; Billaudeau, T. A damage model for fatigue crack propagation from moderate to high $\Delta \mathrm{K}$ levels. Fatigue Fract. Eng. Mater. Struct. 2011, 35, 160-172.

28. Evans, H.E. Mechanism of Creep Fracture, 1st ed.; Elsevier: Amsterdam, The Netherlands, 1984.

29. Cocks, A.C.F.; Leckie, F.A. Creep constitutive equations for damaged materials. Adv. Appl. Mech. 1987, 25, 239-294.

30. Cadek, J. Creep in Metallic Materials, 1st ed.; Elsevier: Amsterdam, The Netherlands, 1988.

31. Mazars, J. A description of micro- and macro-scale damage of concrete structures. Eng. Fract. Mech. 1986, 25, 729-737.

32. Ju, J.W. On energy-based coupled elastoplastic damage theories: Constitutive modeling and computational aspects. Int. J. Solids Struct. 1989, 25, 803-833.

33. Mazars, J.; Pijaudier-Cabot, G. Continuum damage theory-Application to concrete. J. Eng. Mech. 1989, 115, 345-365.

34. Murakami, S.; Kamiya, K. Constitutive and damage evolution equations of elastic-brittle materials based on irreversible thermodynamics. Int. J. Mech. Sci. 1997, 39, 473-486.

35. Kim, S.K.; Lee, C.S.; Kim, J.H.; Kim, M.H.; Lee, J.M. Computational evaluation of resistance of fracture capacity for SUS304L of liquefied natural gas insulation system under cryogenic temperatures using ABAQUS user-defined material subroutine. Mater. Des. 2013, 50, 522-532.

36. Lee, C.S.; Yoo, B.M.; Kim, M.H.; Lee, J.M. Viscoplastic damage model for austenitic stainless steel and its application to the crack propagation problem at cryogenic temperatures. Int. J. Damage Mech. 2013, 22, 95-115. 
37. ASTM E647-13ae1. Standard test method for measurement of fatigue crack growth rates. In Annual Book of ASTM Standards; ASTM International: West Conshohocken, PA, USA, 2013; Volume 3.01.

38. Kim, J.H.; Lee, C.S.; Kim, M.H.; Lee, J.M. Prestrain-dependent viscoplastic damage model for austenitic stainless steel and implementation to ABAQUS user-defined material subroutine. Comput. Mater. Sci. 2013, 67, 273-281.

39. Marshall, C.W.; Hehemann, R.F.; Troiano, A.R. The characteristics of $9 \%$ nickel low carbon steels. Trans. ASM 1962, 55, 135.

40. Syn, C.K.; Jin, S.H.; Morris, J.W. Cryogenic fracture toughness of 9 Ni steel enhanced through grain refinement. Metall. Mater. Trans. A-Phys. Metall. Mater. Sci. 1976, 7A, 1827-1832.

41. Lee, J.M. A Study of Computational Mechanics of Thermal Damage Problem for Structural Members. Ph.D. Dissertation, University of Tokyo, Tokyo, Japan, 1999. (In Japanese)

42. Benallal, A.; Billardon, R.; Lemaitre, J. Continuum damage mechanics and local approach to fracture: Numerical procedures. Comput. Meth. Appl. Mech. Eng. 1991, 92, 141-155.

43. Desmorat, R.; Kane, A.; Seyedi, M.; Sermage, J.P. Two scale damage model and related numerical issues for thermos-mechanical High Cycle Fatigue. Eur. J. Mech. A-Solids 2007, 26, 909-935.

44. Doudard, C.; Calloch, S.; Cugy, P.; Galtier, A.; Hild, F. A probabilistic two-scale model for high-cycle fatigue life prediction. Fatigue Fract. Eng. Mater. Struct. 2005, 28, 279-288.

45. Lemaitre, J.; Sermage, J.P.; Desmorat, R. A two scale damage concept applied to fatigue. Int. J. Fract. 1999, 97, 67-81.

46. Hayhurst, D.R.; Leckie, F.A. Constitutive equations for creep rupture. Acta Metall. 1977, 25, 1059-1070.

(C) 2015 by the authors; licensee MDPI, Basel, Switzerland. This article is an open access article distributed under the terms and conditions of the Creative Commons Attribution license (http://creativecommons.org/licenses/by/4.0/). 